\title{
Development of a One-way Nested Global-regional Air Quality Forecasting Model
}

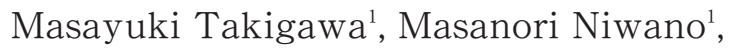 \\ Hajime Akimoto ${ }^{1}$, and Masaaki Takahashi ${ }^{1,2}$ \\ ${ }^{1}$ Frontier Research Center for Global Change, JAMSTEC, Yokohama, Japan \\ ${ }^{2}$ Center for Climate System Research, The University of Tokyo, Kashiwa, Japan
}

\begin{abstract}
We evaluated the ozone distribution over the Kanto region in Japan, calculated by a one-way nested globalregional air quality forecasting $(\mathrm{AQF})$ system. This $\mathrm{AQF}$ system consists of global and regional chemistrytransport models (CTMs). The global CTM is based on CHASER (Chemical Atmospheric General Circulation Model for the Study of Atmospheric Environment and Radiative Forcing) model, whereas the regional CTM is based on the WRF (Weather Research and Forecasting)/ Chem model. The lateral boundary of the regional CTM domain is updated every 3 hours from the global CTM output. An experimental phase for this model system began in July 2006 and has provided 15-hour forecasts of the distribution of ozone concentrations over the Kanto region four times daily. The time evolution and horizontal distribution of chemical species calculated by this AQF system were compared to ground-based observations. Values of statistical measures are within the range suggested by the U.S. Environmental Protection Agency (EPA). By changing the initial value of the meteorological field from 6-hour forecast values to an analysis meteorological field, the average value of the correlation coefficient increased from 0.763 to 0.773 .
\end{abstract}

\section{Introduction}

Ozone has been recognized as a harmful pollutant for decades (e.g., Haagen-Smit et al. 1951). However, until recently, it has been difficult to apply numerical air quality models for routine forecasting of air quality because of the high computational costs of calculating the transport and transformation of chemical species. Some studies have used regional chemistry-transport models (CTMs) for air quality forecasting (e.g., Uno et al. 2003; de Freitas et al. 2005; Eder et al. 2006). Regional CTMs have an advantage in horizontal resolution over global models. On the other hand, global CTMs have the major advantage of being able to estimate intercontinental transport (cf., Lawrence et al. 2003; Takigawa et al. 2005). Takigawa et al. (2005) estimated the contribution of intercontinental and regional long-range transport of $\mathrm{CO}$ to East Asian Pasific rim region. The concentration of surface ozone over Japan is strongly affected by regional transport from East Asian emissions especially in summer (Pochanart et al. 1999). Thus, it is important to consider intercontinental as well as regional transports of pollutants in forecasting air quality over Japan.

In addition to synoptic-scale meteorology, fine-scale meteorology and advection play key roles in the distri-

Corresponding author: Masayuki Takigawa, Frontier Research Center for Global Change, Japan Agency for Marine-Earth Science and Technology, 3173-25 Showa-machi, Kanazawa-ku, Yokohama, Kanagawa 235-0001, Japan. E-mail: takigawa@ jamstec.go.jp. (C2007, the Meteorological Society of Japan. bution of ozone and its precursors over the Kanto plain, which covers the Tokyo metropolitan area (Uno et al. 1996). A global-regional nested model is able to treat long-range transport, in situ chemistry, and local-scale transport within the polluted area simultaneously. Wang et al. (2004) showed that the modeled CO mixing ratio was improved by applying a nested domain to the global CTM with simple chemistry for CO, mainly by the improvement of meteorological features.

We have developed a one-way nested global-regional AQF system with full chemistry based on the CHASER (Sudo et al. 2002) and WRF/Chem (Grell et al. 2005) models. Here, we describe and evaluate our model system.

\section{Numerical model system}

The global CTM part is based on the CHASER model, which is based on CCSR/NIES/FRCGC atmospheric general circulation model (AGCM) version $5.7 \mathrm{~b}$. The basic physical and dynamical features of the model have been described by Hasumi et al. (2004), and modifications of the chemical and dynamical features have been described by Takigawa et al. (2005). Spectral coefficients are triangularly truncated at wavenumber 42 (T42), equivalent to a horizontal grid spacing of about $2.8^{\circ}$. The model has 32 vertical layers that are spaced at approximately $1-\mathrm{km}$ intervals in the free troposphere and lower stratosphere.

The regional CTM part is based on WRF/Chem (Grell et al. 2005). Anthropogenic emission data over Japan, except those from automobiles, are from the JCAP (Japan Clean Air Program) with $1 \mathrm{~km} \times 1 \mathrm{~km}$ resolution (Kannari et al. 2007), and anthropogenic emissions from automobiles over Japan are from EAgrid 2000 (East Asian Air Pollutant Emissions Grid Inventory) with $1 \mathrm{~km} \times 1 \mathrm{~km}$ resolution (K. Murano, personal communication). Surface emissions over China and North and South Korea are taken from REAS (Regional Emission Inventory in Asia) with $0.5^{\circ} \times 0.5^{\circ}$ resolution (Ohara et al. 2007), and surface emissions over Russia are taken from EDGAR (Emission Database for Global Atmospheric Research) with $1^{\circ} \times 1^{\circ}$ resolution (Olivier et al. 1996). Diurnal and seasonal variations in surface emissions are taken into account in the JCAP and EAgrid2000 data, and diurnal variations are also parameterized in emissions from REAS and EDGAR following averaged variations of JCAP. Weekly variation between workdays and holidays is also taken into account in the EAgrid2000 automobile emission data. Note here that emissions based on the statistics in 2000 are applied in the present study. Biogenic emissions are based on Guenther et al. (1993). Figure 1 shows the model domain for the regional CTM part. The outer domain covers Japan with $15-\mathrm{km}$ horizontal resolution (152 × 152 grids for chemical species), and the inner domain covers the Kanto region with $5-\mathrm{km}$ resolution (111 × 111 grids for chemical species). The inner and outer domains in the regional CTM have 31 vertical 


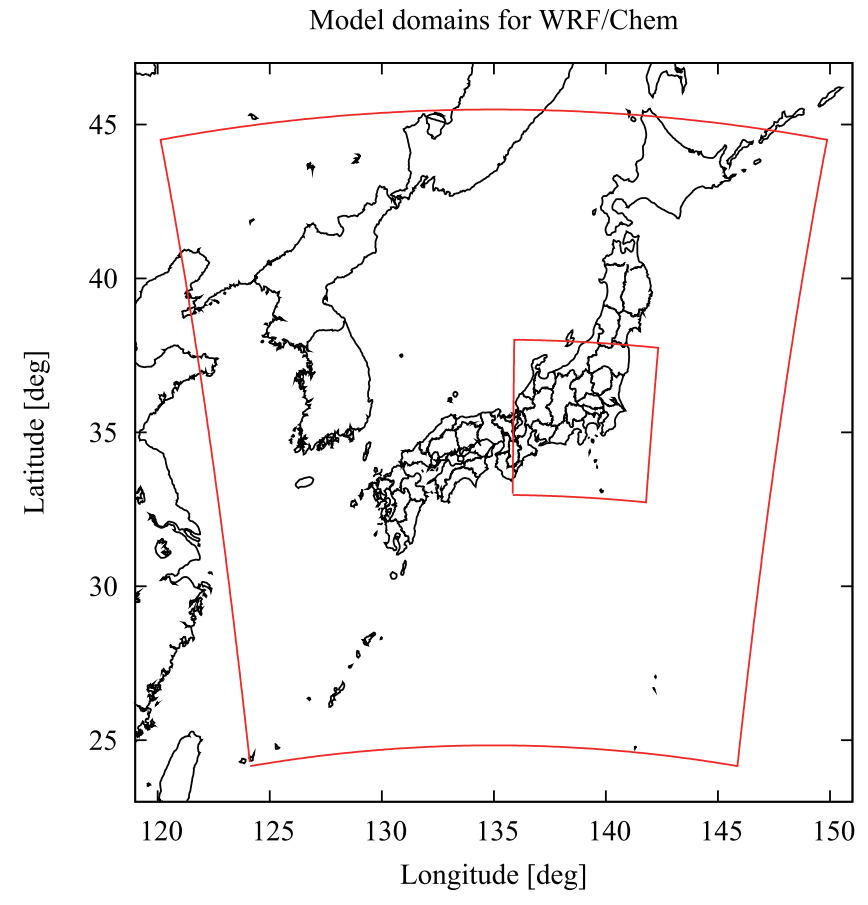

Fig. 1. Model domains for the regional CTM part. The outer domain covers Japan with a $15-\mathrm{km}$ horizontal resolution, and the inner domain covers the Kanto region with a $5-\mathrm{km}$ resolution.

layers up to $100 \mathrm{hPa}$. The two-way nesting calculation is applied in the regional CTM part.

The lateral boundary of chemical species in the regional CTM is taken from the global CTM. The output of the global CTM is linearly interpolated from the Gaussian latitude and longitude grid to a Lambert conformal conic projection for use in the regional CTM. The lateral boundary is updated every 3 hours and linearly interpolated for each time step. We did not include feedback from the regional CTM to the global CTM; that is, the one-way nesting calculation was done between the global and regional CTMs.

The system is driven by meteorological data from the National Centers for Environmental Prediction (NCEP) for the global CTM part and from the mesoscale model (MSM) of the Japan Meteorological Agency (JMA) for the regional CTM part. A 15-hour forecast has been produced four times daily at $00,06,12$, and $18 \mathrm{Z}$ with a lead time of 8-10 hours since July 2006, following a spin-up of 1 month for the global distribution of chemical species. The initial condition of the meteorological field for the regional CTM was taken from the MSM for each forecast, and the initial condition of chemical species was taken from the model output driven by the analysis meteorology.

\section{Results}

To evaluate the model-calculated ozone, the surface ozone mixing ratio was compared to that observed at air quality monitoring stations. There are 251 stations observing surface ozone within the inner domain of the regional CTM as of August 2006. For the comparison of temporal variation, hourly averaged values of observed and modeled surface $\mathrm{O}_{3}$ mixing ratios in August 2006 are shown in Fig. 2. Observed ozone exceeded 100 ppbv from 3 to 6 August at Hanyuu in Saitama Prefecture (36

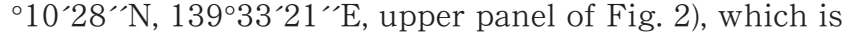
downwind of the Tokyo metropolitan area. The maximum value in the observation was $162 \mathrm{ppbv}$ at $16 Z$ on 3 August. The model successfully reproduced the ozone maximum on 3 August. The maximum simulated value was $137 \mathrm{ppbv}$ in the model. The model also successfully captured the decrease from 3 to 7 August, but failed to show the rapid decrease on 8 August. Three typhoons (Maria, Somai, and Bopha) occurred during this period, and the difficulty of predicting the meteorological field may have led to the overestimation of ozone on 8 August. Both the model and observations indicate low levels of ozone from 14 to 17 August as typhoon 200610 (Wukong) approached Japan. The observed and modeled ozone exceeded 100 ppbv on 11 and 13 August, and the model overestimated the ozone mixing ratio on 19 August. The modeled ozone mixing ratio was 135 ppbv, whereas the observed ozone mixing ratio was 86 ppbv. Daily variation in the ozone mixing ratio at nighttime was well reproduced by the model. The daily minimum of observed and modeled ozone exceeded 10 ppbv on 12, 15, 27, and 28 August; except for these days, the ozone level was almost zero during nighttime. The comparison between the modeled and observed daily variation in surface ozone at Kodaira in Tokyo $\left(35^{\circ} 43^{\prime}\right.$ $\left.42^{\prime \prime} \mathrm{N}, 139^{\circ} 28^{\prime} 38^{\prime \prime}\right)$ is shown in the lower panel of Fig. 2. Maxima of observed and modeled surface ozone at Hanyuu appeared on 3 August, and the observed and modeled ozone mixing ratios at Kodaira were $140 \mathrm{ppbv}$ or higher on 5 and 6 August. The model tended to overestimate the daytime ozone maximum especially for cloudy days, and the discrepancy of daily maximum is larger in urban area compared to that in rural area. To evaluate the model performance, a set of statistical measures provided by the U.S. Environmental Protection Agency (US EPA 1991) was evaluated for stations in the inner domain of the model. The mean normalized bias error (MNBE), the mean normalized gross error (MNGE), and the unpaired peak prediction accuracy (UPA) were $7.1 \%, 9.5 \%$, and $9.4 \%$, respectively. These values are within the criteria range suggested by the U.S. EPA (MNBE $< \pm 10-15 \%$, MNGE $< \pm 30-35 \%$, and UPA $< \pm 15-$ $20 \%)$.

Figure 3 shows the horizontal distribution of observed and modeled surface ozone mixing ratios at $05 Z$ (14 Japan Standard Time [JST]) on 4 August 2006. The observed ozone mixing ratio exceeded $120 \mathrm{ppbv}$ at almost all stations in the western part of Tokyo metropolitan area and the eastern part of Saitama prefecture. The model captured the horizontal distribution of the observed ozone mixing ratio, but the location of the most polluted area was slightly biased westward.

Because 15-hour forecasts have been produced four times daily, each time period was covered by model outputs driven by forecasted and analyzed meteorological fields for the initial condition and lateral boundary. To evaluate the impact of the meteorological field on the distribution of surface ozone, correlation coefficients, MNBE, MNGE, and UPA between observed and modeled surface ozone at 251 stations in the Kanto area in August 2006 were compared among model outputs driven by forecast and analysis meteorological fields. Model outputs driven by the following meteorology were compared: (a) forecast meteorology for the initial condition and lateral boundary, (b) analysis meteorology for the initial condition and forecast meteorology for lateral boundary, and (c) analysis meteorology for the initial condition and lateral boundary. Table 1 shows statistical measures of model performance for surface ozone. Differences between (b) and (c) were quite small for all statistical measures. For both (b) and (c), the 

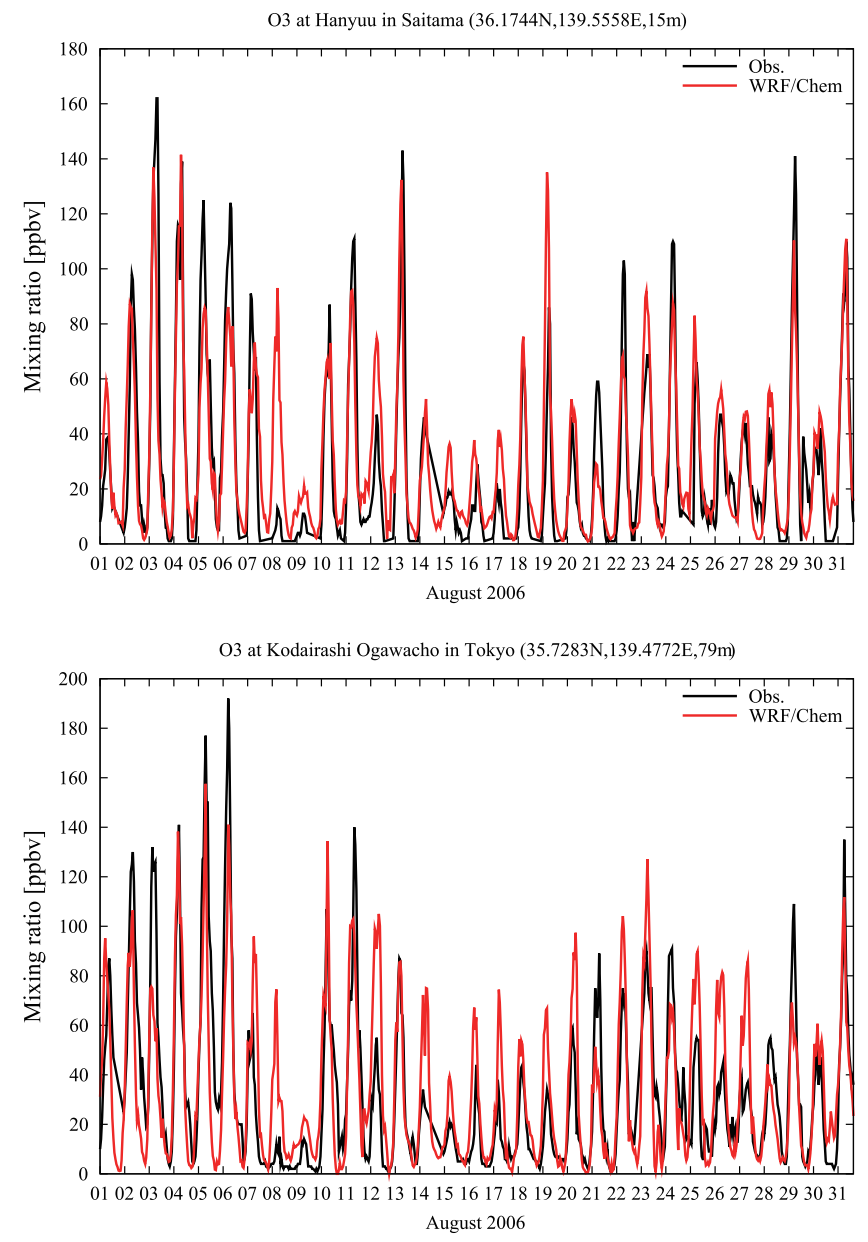

Fig. 2. Hourly observed (black) and modeled (red) surface $\mathrm{O}_{3}$ mixing ratio in August 2006 at Hanyuu in Saitama Prefecture (upper panel) and Kodaira in Tokyo (lower panel).

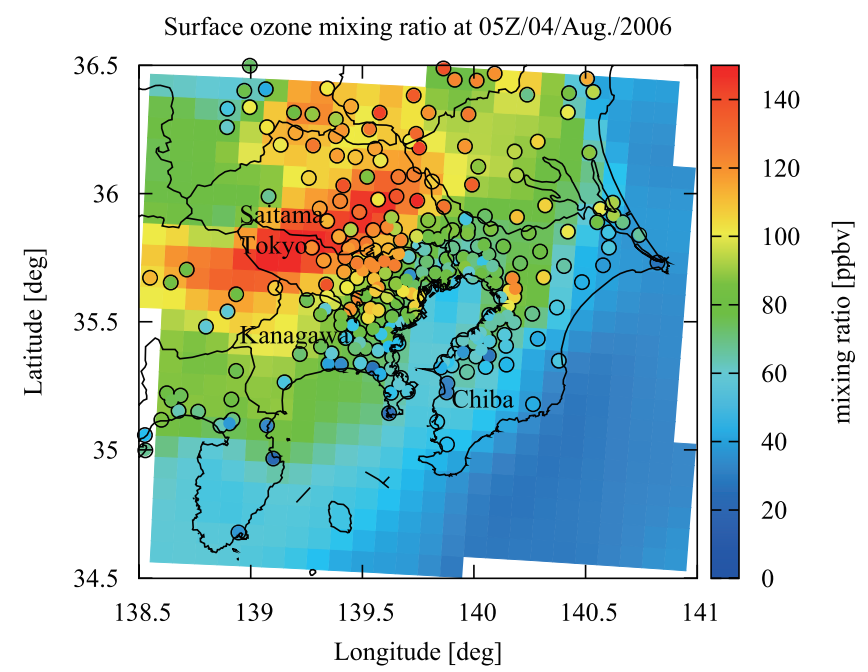

Fig. 3. Observed (colored dots) and modeled (color tones) surface $\mathrm{O}_{3}$ mixing ratio at $05 Z(14 \mathrm{JST})$ on 4 August, 2006.
Table 1. Statistical measures of model performance for 1-h ozone concentration for the model was driven by 06-11 hour forecasts (a), 00-05 hour forecasts (b), and analysis meteorology (c).

\begin{tabular}{ccccc}
\hline & correlation & MNBE(\%) & MNGE(\%) & UPA(\%) \\
\hline (a) & 0.76 & 6.5 & 9.4 & 14.0 \\
(b) & 0.77 & 7.1 & 9.5 & 9.5 \\
(c) & 0.77 & 7.1 & 9.5 & 9.4 \\
\hline
\end{tabular}

initial condition for the meteorological field was analysis meteorology, and the difference in the relatively short-range forecast (less than 6 hours) of ozone distribution caused by the difference in the lateral boundary was negligibly small. In contrast, UPA increased in (a) compared to (b) and (c), at $14.0 \%$ in (a), and 9.5\% and $9.4 \%$ in (b) and (c), respectively. These results suggest that the initial condition of the meteorological field can affect the short-range (less than 12 hours) forecast of ozone distribution. Although the forecasted ozone derived from (a) had smaller correlations than (b) and (c), approximately $83 \%$ of stations in the Kanto region had correlations of 0.70 or higher.

\section{Summary and discussion}

A one-way, nested, global-regional AQF system was developed to simultaneously treat long-range transport and local transport and in situ chemistry over the Kanto plain. The model system produced 15-hour forecasts of the distribution of chemical species since July 2006. Comparison of the modeled surface ozone with observations from air quality monitoring stations in August 2006 shows that the model generally reproduced diurnal and daily variations in ozone over the Kanto plain. The model could not reproduce ozone levels during typhoon events, suggesting that improvements to the meteorological part of the regional model are needed for more precise air quality forecasting. To estimate the effect of the meteorological field on air quality forecasting, the distribution of correlation coefficients was compared among model outputs that had been driven by analysis and forecast meteorological fields. The result suggests that the lateral boundary of the meteorological field may have little effect on the distribution of surface ozone, but the initial condition of the meteorological field can affect the distribution of surface ozone. Values of statistical measures such as MNBE, MNBE, and UPA are within the range suggested by the U.S. EPA. This result encourages us to apply our model as a public warning for oxidants.

One approach for improving air quality forecasts is the use of an ensemble forecast system (Monache and Stull 2003; Wilczak et al. 2006). The initial condition of chemical species is also a key factor for air quality forecasts. Data assimilation such as by the ensemble Kalman filter (EnKF; Evensen 1994) or four-dimensional variational data assimilation (4D-Var) would be useful for the initialization of the chemistry field.

\section{Acknowledgments}

We thank G. Grell, K. Sudo, and all others responsible for the development of the WRF/Chem and CHASER models. We also thank those responsible for observations at air quality monitoring stations. This study was 
supported by an internal special project fund of the Japan Agency for Marine-Earth Science and Technology (JAMSTEC).

\section{References}

de Freitas, E. D., L. D. Martins, P. L. da Silva Dias, and M. de Faitima Andrade, 2005: A simple photochemical module implemented in RAMS for tropospheric ozone concentration forecast in the metropolitan area of São Paulo, Brazil: Coupling and validation. Atmos. Environ., 39, 6352-6361, doi:10.1016/j.atmosenv.2005.07.017.

Eder, B., D. Kang, R. Mathur, S. Yu, and K. Schere, 2006: An operational evaluation of the Eta-CMAQ air quality forecast model. Atmos. Environ., 40, 48944905, doi:10.1016/j.atmosenv.2005.12.062.

Evensen, G., 1994: Sequential data assimilation with a nonlinear quasi-geostrophic model using Monte Carlo methods to forecast error statistics. J. Geophys. Res., 99, 10143-10162.

Grell, G. A., S. E. Peckham, R. Schmitz, S. A. McKeen, G. Frost, W. C. Skamarock, and B. Eder, 2005: Fully coupled "online" chemistry within the WRF model. Atmos. Environ., 39, 6957-6975.

Guenther, A., P. R. Zimmerman, P. Harley, R. K. Monson, and R. Fall, 1993: Isoprene and monoterepene emission rate variability: Model evaluations and sensitivity analyses. J. Geophys. Res., 98D, 1260912617.

Haagen-Smit, A., E. Darley, M. Zaitlin, H. Hull, and W. Noble, 1951: Investigation of injury to plants from air pollution in the Los Angeles area. Plant Physiol., 27, 18-24.

Hasumi, H., S. Emori, A. Abe-Ouchi, A. Hasegawa, T. Inoue, M. Kimoto, S. Matsumura, T. Nagashima, H. Nakano, T. Nishimura, T. Nozawa, R. Ohgaito, A. Oka, N. Okada, K. Ogochi, T. Ogura, F. Saito, K. Saito, T. Sakamoto, T. Segawa, T. Soga, K. Sudo, A. Sumi, T. Suzuki, T. Suzuki, H. Takahashi, K. Takata, T. Takemura, M. Takigawa, Y. Tsushima, M. Watanabe, S. Watanabe, and T. Yokohata, 2004: K-1 Coupled GCM (MIROC) Description. Technical report, CCSR, Kashiwa, Chiba, Japan.

Kannari, A., Y. Tonooka, T. Bada, and K. Murano, 2007: Development of multiple-species $1 \mathrm{~km} \times 1 \mathrm{~km}$ resolution hourly basis emissions inventory for Japan. Atmos. Environ., 41, 3428-3439, doi:10.1016/j. atmosenv.2006.12.015.

Lawrence, M., P. Rasch, R. Kuhlmann, J. Williams, H. Fischer, M. de Reus, J. Lelieveld, P. Crutzen, M. Scultz, P. Stier, H. Huntrieser, J. Heland, A. Stohl, C. Forster, H. Elbern, H. Jakobs, and R. Dickerson, 2003: Global chemical weather forecasts for field campaign planning: predictions and observations of large-scale features during MINOS, CONTRACE, and INDOEX. Atmos. Chem. Phys., 3, 267-289.

Monache, L. D., and R. B. Stull, 2003: An ensemble airquality forecast over western Europe during an ozone episode. Atmos. Env., 37, 3469-3474, doi: 10.1016/S1352-2310(03)00475-8.

Ohara, T., H. Akimoto, J. Kurokawa, N. Horii, K. Yamaji,
X. Yan, and T. Hayasaka, 2007: Asian emission inventory for anthropogenic emission sources during the period 1980-2020. Atmos. Chem. Phys. Dis., 7, 6843-6902, doi:www.atmos-chem-physdiscuss. net $/ 7 / 6843 / 2007 /$.

Olivier, J. G. J., A. F. Bouwman, C. W. M. Van der Maas, J. J. M. Berdowski, C. Veldt, J. P. J. Bloos, A. J. H. Visschedijk, P. Y. J. Zandveld, and J. L. Haverlag, 1996: Description of EDGAR Version 2.0. A set of global emission inventories of greenhouse gases and ozonedepleting substances for all anthropogenic and most natural sources on a per country basis and on $1^{\circ} \times 1^{\circ}$ grid. RIVM/TNO rep., RIVM, Bilthoven, number nr. 711060002, 1006.

Pochanart, P., J. Hirokawa, Y. Kajii, H. Akimoto, and M. Nakao, 1999: Influence of regional-scale anthropogenic activity in northeast Asia on seasonal variations of surface ozone and carbon monoxide observed at Oki, Japan. J. Geophys. Res., 104, 36213631, doi:10.1029/1998JD10071.

Sudo, K., M. Takahashi, J. Kurokawa, and H. Akimoto, 2002: CHASER: A global chemical model of the troposphere 1. Model description. J. Geophys. Res., 107, doi:10.1029/2001 JD001113.

Takigawa, M., K. Sudo, H. Akimoto, K. Kita, N. Takegawa, Y. Kondo, and M. Takahashi, 2005: Estimation of the contribution of intercontinental transport during PEACE campaign by using a global model. J. Geophys. Res., 110, doi:10.1029/ 2005JD006226.

Uno, I., G. Carmichael, D. Streets, Y. Tang, J. Yienger, S. Satake, Z. Wang, J.-H. Woo, S. Guttikunda, M. Uematsu, K. Matsumoto, H. Tanimoto, K. Yoshioka, and T. Iida, 2003: Regional chemical weather forecasting system CFORS: Model descriptions and analysis of surface observations at Japanese island stations during the ACE-Asia experiment. J. Geophys. Res., 108, doi:10.1029/2002 JD002845.

Uno, I., T. Ohara, and S. Wakamatsu, 1996: Analysis of wintertime $\mathrm{NO}_{2}$ pollution in the Tokyo Metropolitan area. Atmos. Env., 30, 703-713.

US EPA, 1991: Guideline for regulatory application of the urban airshead model. Number EPA-450/4-91-013 in US EPA Report, Office of Air and Radiation, Office of Air Quality Planning and Standards, Technical Support Division, Research Triangle Park, North Carolina, US.

Wang, Y., M. McElroy, D. Jacob, and R. Yantosca, 2004: A nested grid formulation for chemical transport over Asia: Application to CO. J. Geophys. Res., 109, doi:10.1029/2004JD005237.

Wilczak, J., S. McKeen, I. Djalalova, G. Grell, S. Peckam, W. Gong, V. Bouchet, R. Moffet, J. McHenry, J. McQueen, P. Lee, Y. Tang, and G. R. Carmichael, 2006: Bias-corrected ensemble and probabilistic forecasts of surface ozone over eastern North America during the summer of 2004. J. Geophys. Res., doi: 10.1029/2006JD007598.

Manuscript received 7 May 2007, accepted 27 July 2007 SOLA: http://www.jstage.jst.go.jp/browse/sola/ 